\title{
Utilisation of fine needle aspiration cytology and biopsy in Sokoto, Nigeria: A five-year review
}

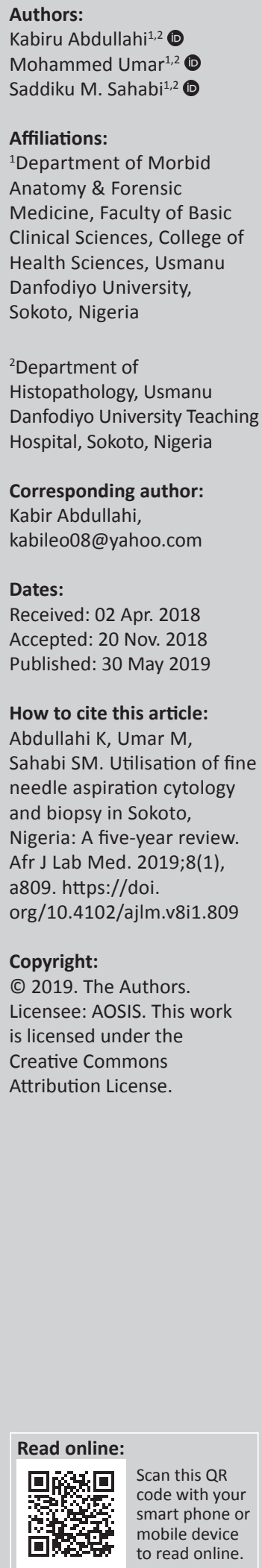

The histopathology department of Usmanu Danfodiyo University Teaching Hospital in Sokoto, Nigeria, conducted a total of 1435 fine needle aspiration biopsies from 1 January 2011 to 31 December 2015, constituting 30\% of cytology specimens received. The most common site for the procedure was the breast (655 cases, $45.6 \%)$, and 893 cases $(63.3 \%)$ were neoplastic lesions. Even in resource-poor settings, this underutilised procedure is useful for patient management.

Keywords: fine needle; aspirate, cytology.

\section{Introduction}

Fine needle aspiration cytology (FNAC) refers to a procedure whereby cells are obtained from a lump, mass or suspicious lesion using a 'fine bore' needle (22-27 G) with the aim of microscopic examination of the cells after appropriate staining techniques. The FNAC procedure may be done with or without the use of a syringe. It may be performed guided by palpation or by an ultrasound scan. . $^{1,2,3,4,5}$

The first reports of the FNAC procedure date back to the 19th century and since then, there have been tremendous developments in its acceptability and utility as part of the diagnostic armamentarium. ${ }^{3,4,5}$ The procedure is a simple, cheap, reliable, fast and fairly accurate tool, which, in most parts of the developed world, has become routine in medical practice. ${ }^{2}$ However, this may not be the case in resource-constrained settings; for example, it has been underutilised in Nigeria, as reported by Malami and others.,

There is a need to increase awareness of the procedure, especially with regard to its pivotal role as a cost-effective means of dramatically modifying the course of disease management in patients suspected of having neoplasms. Also, information about its availability and usefulness will assist healthcare policymakers to channel resources towards developing this field of pathology practice in developing countries. ${ }^{6,7,8}$

Virtually every organ or region of the body is accessible to the fine needle for aspiration biopsy. It is minimally invasive, gives the least discomfort (even in children) and does not require elaborate patient preparation, such as anaesthesia. Results can be available within a few hours. ${ }^{5,6,8,9}$

\section{Methods}

\section{Ethical considerations}

Ethical clearance for the study was sought and obtained from the Hospital Research and Ethics Committee of Usman Danfodiyo University Teaching Hospital, Sokoto, Nigeria. The ethical approval number is: UDUTH/HREC/2018/649.

\section{Setting}

The study was conducted in the Department of Histopathology at Usmanu Danfodiyo University Teaching Hospital, Sokoto, a tertiary health institution situated in the north-west region of Nigeria. It provides tertiary healthcare services to (but not exclusively) the Sokoto, Kebbi, Zamfara and Niger states. It also receives referrals from the Republic of Niger, a neighbouring country. Services rendered in the histopathology department of the hospital include histopathology of surgical biopsies and research specimens, cytopathology (including FNAC), frozen section, immunohistochemistry and autopsy. 


\section{Population}

Most of the patients presented at the histopathology department for the procedure were on referral after initially being seen by attending physicians in the outpatient units. A few were inpatients, which required the histopathologist to perform the FNAC in the wards. In both cases, the requesting physicians filled out histopathology requisition forms indicating the site for the procedure and other relevant clinical details. The fine needle aspiration was done by the histopathologist, predominantly using a palpation guide.

\section{Sampling}

Universal sampling was employed, in which all cases registered as fine needle aspiration biopsy in the departmental records (reception registers, bench books, request forms, etc.) over the period 1 January 2011 to 31 December 2015 (five years) were consecutively selected specifically with respect to the patients' age, sex, and site of biopsy. Corresponding microscope slides prepared in quadruplicate (each replicate stained with Papanicolaou stain, Giemsa and hematoxylin or eosin) were retrieved from the departmental archive and re-viewed via light microscopy, using organ specific guidelines. Faded slides were re-stained where possible; missing slides were excluded from the study.

The data generated were entered into a Microsoft Excel 2007 edition (Microsoft Corporation, Redmond Washington, United States) spreadsheet, validated, exported to SPSS version 20 (IBM SPSS Statics for Windows, Version 20.0; IBM Corp, Armonk, New York, United States) for analysis and results were presented as frequency distribution tables.

\section{Results}

Over the five-year period of the study, a total of 1685 FNAC procedures were performed, of which 1435 were included in the study. This represented $30.0 \%$ of all cytology specimens seen during the same period. The age range of patients was two weeks to 100 years, with a mean age of 32.7 years.

The procedure was most frequently performed in patients within the age range of 21-30 years and least performed in those less than one year old (Table 1). A male-to-female sex ratio of approximately 1:3 was observed, depicting a female preponderance. This ratio changed to approximately 1:1 when breast FNAC was excluded.

The breasts were the most common site for FNAC, with $655(45.6 \%)$ cases, followed by $378(26.3 \%)$ head and neck cases and 206 (14.4\%) lymph node cases. Abdominal viscera were the least accessed organs with 27 (1.9\%) cases (Table 2). Non-neoplastic lesions ('inflammation' and 'reactive') accounted for a total of $250(17.4 \%)$ cases, while neoplastic lesions ('benign' and 'malignant') accounted for 893 (62.3\%) cases. Specifically, there were $740(51.6 \%)$ benign lesions and $153(10.7 \%)$ malignant lesions. There were 218 (15.2\%) lesions with suspicious features.
TABLE 1: Sex and age distribution of fine needle aspiration biopsy in Sokoto.

\begin{tabular}{lcc}
\hline Variable & Frequency & Percentage \\
\hline Sex & 391 & 27.2 \\
Male & 1043 & 72.7 \\
Female & 1 & 0.1 \\
Unspecified & 1435 & 100.0 \\
Total & & \\
Age group & 9 & 0.6 \\
$<1$ year & 124 & 8.6 \\
$1-10$ & 230 & 16.0 \\
$11-20$ & 364 & 25.4 \\
$21-30$ & 288 & 20.0 \\
$31-40$ & 219 & 15.4 \\
$41-50$ & 118 & 8.2 \\
$51-60$ & 52 & 3.6 \\
$61-70$ & 17 & 1.2 \\
$71+$ & 14 & 1.0 \\
Unspecified & 1435 & 100.0 \\
Total & & \\
\hline
\end{tabular}

TABLE 2: Distribution of fine needle aspiration biopsy by diagnosis, site and malignant cytologic diagnosis in Sokoto.

\begin{tabular}{|c|c|c|}
\hline Variable & Frequency & Percentage \\
\hline \multicolumn{3}{|l|}{ Diagnosis } \\
\hline Acellular/inadequate & 74 & 5.1 \\
\hline Inflammation & 212 & 14.8 \\
\hline Reactive & 38 & 2.6 \\
\hline Suspicious & 218 & 15.2 \\
\hline Benign & 740 & 51.6 \\
\hline Malignant & 153 & 10.7 \\
\hline Total & 1435 & 100.0 \\
\hline \multicolumn{3}{|l|}{ Site/region/organ } \\
\hline Head \& neck & 378 & 26.3 \\
\hline Ocular & 31 & 2.2 \\
\hline Breast & 655 & 45.6 \\
\hline Lymph node & 206 & 14.4 \\
\hline Soft tissue \& osteoarticular & 136 & 9.5 \\
\hline Viscera & 27 & 1.9 \\
\hline Unspecified & 2 & 0.1 \\
\hline Total & 1435 & 100.0 \\
\hline \multicolumn{3}{|c|}{ Site/region/organ (of malignant cytology) } \\
\hline Breast & 64 & 41.8 \\
\hline Head \& neck & 39 & 25.5 \\
\hline Lymph nodes & 16 & 10.5 \\
\hline Ocular & 18 & 11.8 \\
\hline Soft tissue \& osteoarticular & 9 & 5.9 \\
\hline Viscera & 7 & 4.6 \\
\hline Total & 153 & 100.0 \\
\hline
\end{tabular}

\section{Discussion}

A total of 1435 FNAC procedures were performed over the five-year period studied, constituting approximately $30 \%$ of all cytology specimens seen in the department. This figure is much higher than that reported from north-central Nigeria where a rate of 97 FNAC per year (over three years) was observed. ${ }^{9}$ However, it is comparable to Faduliye's study from south-west Nigeria, where a total of 1855 cases (representing FNAC specimens and cytology specimens obtained by other means) were performed over a period of six years (although that study also included cytology specimens obtained by other means). ${ }^{1}$ These studies show that the procedure is still in the early stages of widespread 
use as compared to figures from centres in developed countries that report up to 1000 cases per year. ${ }^{5}$

We observed that the highest frequencies were seen in the 21-30 years and 31-40 years age ranges. FNAC was also done in individuals at extreme ages $(9[0.6 \%]$ who were younger than 1 year and 17 [1.2\%] who were older than 71 years) showing that the procedure is applicable irrespective of the patient's age. These compare favourably with studies from Nigeria and other countries. ${ }^{1,5,9,10}$

The frequency of FNAC among women was higher with $1043(72.1 \%)$ cases as compared to men, and this may reflect the higher frequency of breast FNAC, which accounted for $655(45.6 \%)$ of all FNAC cases. This finding compares with the observations of Mohammed et al. from north-east Nigeria and Vhriterhue from north central Nigeria. $7,8,9$

Only $153(10.7 \%)$ of the cases were malignant, whereas 740 $(51.6 \%)$ were benign. This is an important feature to note as this outcome underscores the usefulness of the procedure for the immediate triage of patients, which significantly alters the clinical management outline. Other workers have also noticed a similar usefulness of the procedure. . $^{1,8,9,11}$

As Vhriterhue and others have noted, a high frequency of 'grey zone' diagnosis (e.g. 'indeterminate') potentially undermines the usefulness of the FNAC diagnosis. In our centre, we had $15.2 \%$ of such 'grey zone' ('suspicious') cases and this needs to be improved upon to reduce the dilemma and further distress placed on surgeons and patients. ${ }^{9,11}$ To achieve this, it is recommended that the FNAC (especially for barely palpable lesions or lesions located in anatomically difficult sites to access) be performed under ultrasound guide, for example. This will further improve the yield of the aspiration.

\section{Conclusion}

Fine needle aspiration cytology is a useful tool in medical practice. Even in nascent centres like ours, in north-west Nigeria, it has found a place in pathology practice. It can be performed on all patients irrespective of age and sex. It is a cost-effective simple procedure, not usually requiring anaesthesia and can be performed on outpatients as well as inpatients, usually with the pathologist being guided by palpation of the lesion. Its outcome immediately makes a difference in clinical judgment and patient management. It is recommended that there should be capacity building by encouraging the training and retraining of pathologists, and thus encouraging sub-specialisation in this underutilised area of pathology in centres practising in resource-poor regions. In the same vein, resources need to be channelled towards establishing FNAC clinics even at the level of primary healthcare, thereby preventing the frequently reoccurring theme of patients presenting with advanced stage malignant neoplasms. There is a need to correlate cytological and histological findings to further encourage confidence in the procedure.

\section{Acknowledgements Competing interests}

The authors declare that they have no financial or personal relationships that may have inappropriately influenced them in writing this paper.

\section{Authors' contributions}

K.A. developed the concept of the study and drafted the literature review. M.U. drafted the literature review and proofread the final manuscript. S.M.S. drafted the literature review and proofread the final manuscript.

\section{Source of support}

None.

\section{Disclaimer}

The views expressed in the article are those of the authors and not an official position of the institution.

\section{References}

1. Faduyile FA, Soyemi SS, Oyewole OO. Cytopathology practice in Lagos, Nigeria: Our experience. Ann Trop Pathol. 2016;7(2) July-December:117-122.

2. Bibbo M, Wilbur DC, editors. Comprehensive cytopathology. 3rd ed. Philadelphia, PA: Saunder Elsevier; 2008.

3. Shehu SM, Rafindadi AH. Use of fine needle aspiration biopsy (FNAB) in the management of breast diseases in Ahmadu Bello University Teaching Hospital, Zaria. Niger J Surg. 1999;6;6-9.

4. Pindiga UH, Abubakar H. Fine needle aspiration cytology: Appropriate technology, that is quick, safe and cheap. Sahel Med J. 2001;4:95-96.

5. Das DK. Fine needle aspiration cytology: Its origin, development and present status with special reference to a developing country, India. Diagn Cytopathol. 2003;28:345-351. https://doi.org/10.1002/dc.10289

6. Malami SA, Ochicha O. A review of the utilization of fine needle aspiration in clinical practice and research in Nigeria. Cytojournal. 2011;8:12. https://doi. org/10.4103/1742-6413.82277

7. Bhursnamath B. Fine needle aspiration biopsy cytology (FNAB) in diagnosis of tumours. West Afr J Med. 1986;5:41-47.

8. Ngadda HA, Ajayi NA, Ahidjo A, Pindiga UH, Mustapha SK, Khalil MI. Fine needle aspiration cytology diagnosis of liver diseases in the University of Maiduguri Teaching Hospital, Maiduguri. Afr J Med Sci. 2004:33:255-257.

9. Vhriterhire RA, Orkuma JA, Ngbea JA, Eke BA, Jobo GTA, Adekwu A. Cytology services utilisation pattern in North Central Nigeria. Br J Med Med Res. 2016:18(11):1-6. https://doi.org/10.9734/BJMMR/2016/29774

10. McPherson K, Steel CM, Dixon JM. Breast cancer - Epidemiology, risk factors, and genetics. Br Med J. 2000;321(7261):624-628. https://doi.org/10.1136/bmj.321. 7261.624

11. Duduyemi BM, Owusu-Afiyie O, Dnagquah KO, Osakunor DN. Cytopathology practice in Kumasi: A 2 year retrospective audit. J Cytol. 2017;34:22-26. https:// doi.org/10.4103/0970-9371.197593 